\title{
Identification and improvement of critical joints in CLT construction without weather protection
}

\author{
Kristo Kalbe ${ }^{1 *}$, Villu $\mathrm{Kukk}^{1}$, Targo Kalamees ${ }^{2,1}$ \\ ${ }^{1}$ nZEB Research Group, Tallinn University of Technology, Tallinn, Estonia \\ ${ }^{2}$ Smart City Center of Excellence (Finest Twins), Tallinn University of Technology, Tallinn, Estonia
}

\begin{abstract}
Wetting of timber structures during erection can have a harmful effect on their durability and could lead to adverse health effects. The probability of dampness related problems is very high when timber is exposed to free water. However, it is not always possible to implement full weather protection and thus there is a need for cost optimal solutions to increase the moisture safety of precipitation-exposed timber construction. In this study we observed the construction works and monitored the timber moisture content (MC) of a cross-laminated timber (CLT) building and proposed a set of activities and designed connection details that could help to avoid moisture ingress during the installation of CLT panels. Our findings showed that the most sensitive area to wetting is the end-grain on the CLT panel and the MC remained within critical limits in structures where drying was prohibited. Therefore, the most vulnerable section of the CLT structure is the foundation connection. We suggest using liquid-applied membrane coating on the cut edges of CLT panels to protect the end grain and to cover the horizontal CLT panels with self-adhesive membranes and vertical CLT panels with temporary clear weather protection foils.
\end{abstract}

\section{Introduction}

Wetting of timber structures during erection can have a harmful effect on their durability [1-3] and could lead to adverse health effects due to microbial growth [4-7]. Furthermore, the Construction Products Regulation [8] states that "The construction works must be designed and built in such a way that they will ... not be a threat to the hygiene or health and safety $\ldots$ as a result of ... dampness in parts of the construction works or on surfaces within the construction works."

The probability of dampness related problems is very high when timber is exposed to free water $[9,10]$. Mjörnell and Olsson recommend, in their recent study, to use moisture safe and robust structures, weather protection, and moisture safe construction methods [11]. Using whole building weather protection (such as a tent) would be the safest method to achieve this. However, there is a reluctancy on the construction market to implement this procedure because of concerns about increasing construction costs and thus it is an ongoing practice to erect timber buildings without protecting them from precipitation. A cost optimal solution between the two approaches would be implementing specific construction methodology to increase the moisture safety of precipitation-exposed timber construction.

In this study we analysed the construction works of a cross-laminated timber (CLT) building to determine the most critical joints of this CLT construction and proposed a set of activities that could help to avoid moisture ingress during the installation of CLT panels.

\section{Methods}

In this work, we used the observational method to investigate wetting incidents during the construction of a two-storey building with a total floor area of $1320 \mathrm{~m}^{2}$ (Fig. 1). The building is located in Estonia where there is a cold and humid continental climate with warm summers - Dfb under the Köppen-Geiger climate classification [12]. All of the above-ground load bearing structures, including exterior walls, intermediate walls, and ceilings were made of CLT or glulam. This makes the building a good reference to other similar buildings as the main joint solutions presented here can be found in most CLT buildings. The walls were insulated with polyisocyanurate (PIR) insulation boards and the roof was insulated with expanded polystyrene (EPS) boards. The construction was exposed to precipitation and protective measures

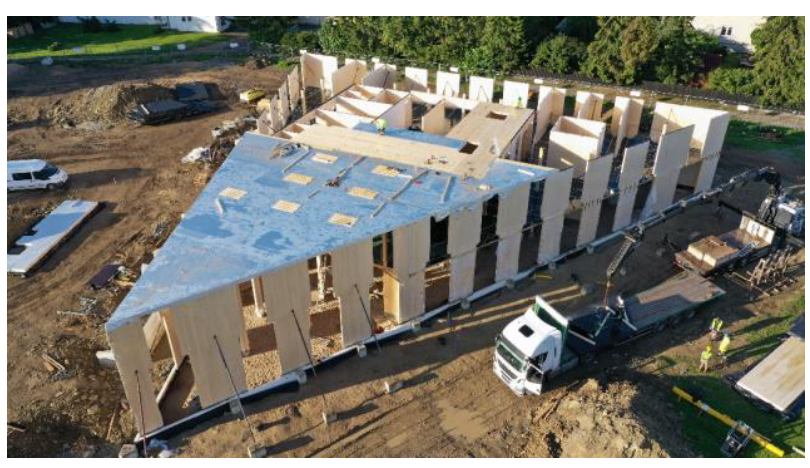

Fig. 1. Observed CLT construction without weather protection.

\footnotetext{
* Corresponding author: kristo.kalbe@taltech.ee
} 
were used partially. For example, the CLT panels were covered with polyethylene (PE) foil during transport, but the foil was partially removed after the installation of the CLT panels. Furthermore, there was no moisture safety management implemented. Therefore, the timber structure was vulnerable to moisture ingress and thus proved to be suitable to determine the critical joints of precipitation-exposed CLT construction.

We observed particular aspects of the construction process and wetting incidents without further interaction similarly to human sciences [13], where the observational method is common [14]. We visited the site regularly and captured as much of the occurring issues as objectively and promptly as possible. We looked for signs of water ingress - such as stained wood, shrinkage or swelling, or the presence of free water on the surface of the structures. For covered areas we looked for gaps and/or faults in the material and further inspected the timber structure beneath it. We then measured the timber moisture content (MC) and marked the point of measurement for future repeated measurements (Fig. 2, left). We also made photos and videos of the findings and of the overall construction process and analysed them later. We proceeded to analyse the possible water ingress pathways and proposed measures and construction methods to avoid or lessen possible water damage.

MC in CLT structures was measured according to the EN 13183-2:2002 standard with an electrical resistancebased wood moisture meter, the Gann Hydromette LG 3. The measuring range of the moisture meter was 4 to $30 \%$ with a resolution of $0.1 \%$ and an accuracy of $\pm 1 \%$. The uncertainty increases considerably with measurement values over fibre saturation point $(\approx 30 \%)$. Nevertheless, we opted to report all the measurement readings as is. Values over $30 \%$ have a lower accuracy but are helpful to describe the extent of wetting. The moisture meter consisted of a measuring device and a ram-in electrode (Fig. 2, left). We used $60 \mathrm{~mm}$ long Teflon insulated pins for the ram-in electrode. The pins had $10 \mathrm{~mm}$ long uninsulated peaks that made it possible to measure the MC at different depths in the CLT. We selected a fixed depth of $30 \mathrm{~mm}$ (measuring range 20 to $30 \mathrm{~mm}$, Fig. 2, right). The $\mathrm{MC}$ was measured at a height of $30 \mathrm{~mm}$ from the lower edge of the CLT wall panels, as the preliminary observations suggested that the cut edges of wall panels are the most critical. We chose 20 measurement points
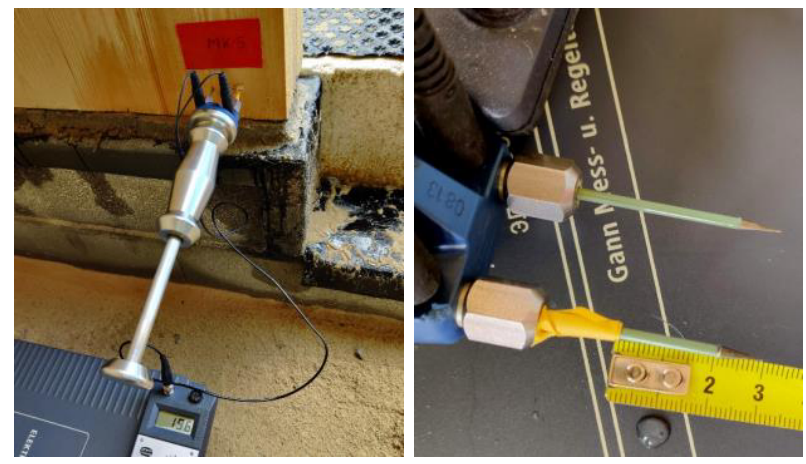

Fig. 2. Measuring the timber MC from a previously marked spot (left) using Teflon insulated electrode pins (right).

Measuring depth was marked on the pins with contrasting tape. around the perimeter and, in addition, 3 points on the intermediate ceiling to intermediate wall and 2 intermediate ceiling to window connections (measured from the end-grain). We made a total of six measurement rounds on the $13^{\text {th }}$ September, $4^{\text {th }}$ October, $25^{\text {th }}$ October, $11^{\text {th }}$ November and $19^{\text {th }}$ December 2019 and $31^{\text {th }}$ January 2020. In order to take into account the possible influence of weather on the $\mathrm{MC}$, we acquired weather data (hourly values of outdoor temperature, relative humidity $(\mathrm{RH})$, and precipitation) from the local national weather station (Fig. 3).

To estimate the criticality of $\mathrm{MC}$, we used the limit values of $17 \%$ for possible risk of mould growth $[15,16]$, $20 \%$ for low and over $26 \%$ for higher risk of decay initiation [17].

\section{Results and Discussion}

\subsection{On-site measurements and findings}

During the first observation of the construction process, we mapped the most critical locations, i.e. places where the CLT panels received most wetting. We determined that the main focus in further MC measurements should be at the exterior wall to foundation connection around the perimeter of the building.

In Figure 3 there is a summarising graph of weather data presented in the time axis, including different construction phases that occurred over the course of the observation period. Precipitation occurred throughout the construction time and there were only a few completely dry periods, which is common during autumn in a cold and humid climate.

The installation of CLT panels (from 14.08.2019 to 06.09.2019) took place during the period of highest precipitation amounts. The average precipitation amount was $1.4 \mathrm{~mm} / \mathrm{h}$ and the maximum reached $8.5 \mathrm{~mm} / \mathrm{h}$. We made the first round of MC measurements on the $13^{\text {th }}$ September, after the CLT panels were installed. The ceilings were covered with water and water was flowing down the walls. It was clear that the CLT structures had been exposed to a sizeable amount of water. MC exceeded $17 \%$ in most measurement points around the perimeter, over $20 \%$ in more than half and over $26 \%$ in three points. The average outdoor temperature during the period was $17^{\circ} \mathrm{C}$ and the average relative humidity was $80 \%$. Figure 4 shows all the measured values and calculated average values for each visit. Smoothed lines are presented between the average values of each visit to show the trend of MC over the visits.

The installation of the panels was followed by the sealing of the skylight shafts, between the $16^{\text {th }}$ and $20^{\text {th }}$ September, and the installation of the roof insulation and cover membrane, between the $25^{\text {th }}$ September and $10^{\text {th }}$ October. During this period the precipitation amount was lower (average $0.6 \mathrm{~mm} / \mathrm{h}$, maximum $4.6 \mathrm{~mm} / \mathrm{h}$ ). The $\mathrm{MC}$ during this period, measured on $4^{\text {th }}$ October, was above $17 \%$ in almost all points around the perimeter and exceeded $20 \%$ in most points. We detected an increase of the overall average $\mathrm{MC}$ to $22.3 \%, 1.1 \%$ higher compared to the average of the first measurements $(21.2 \%)$. 


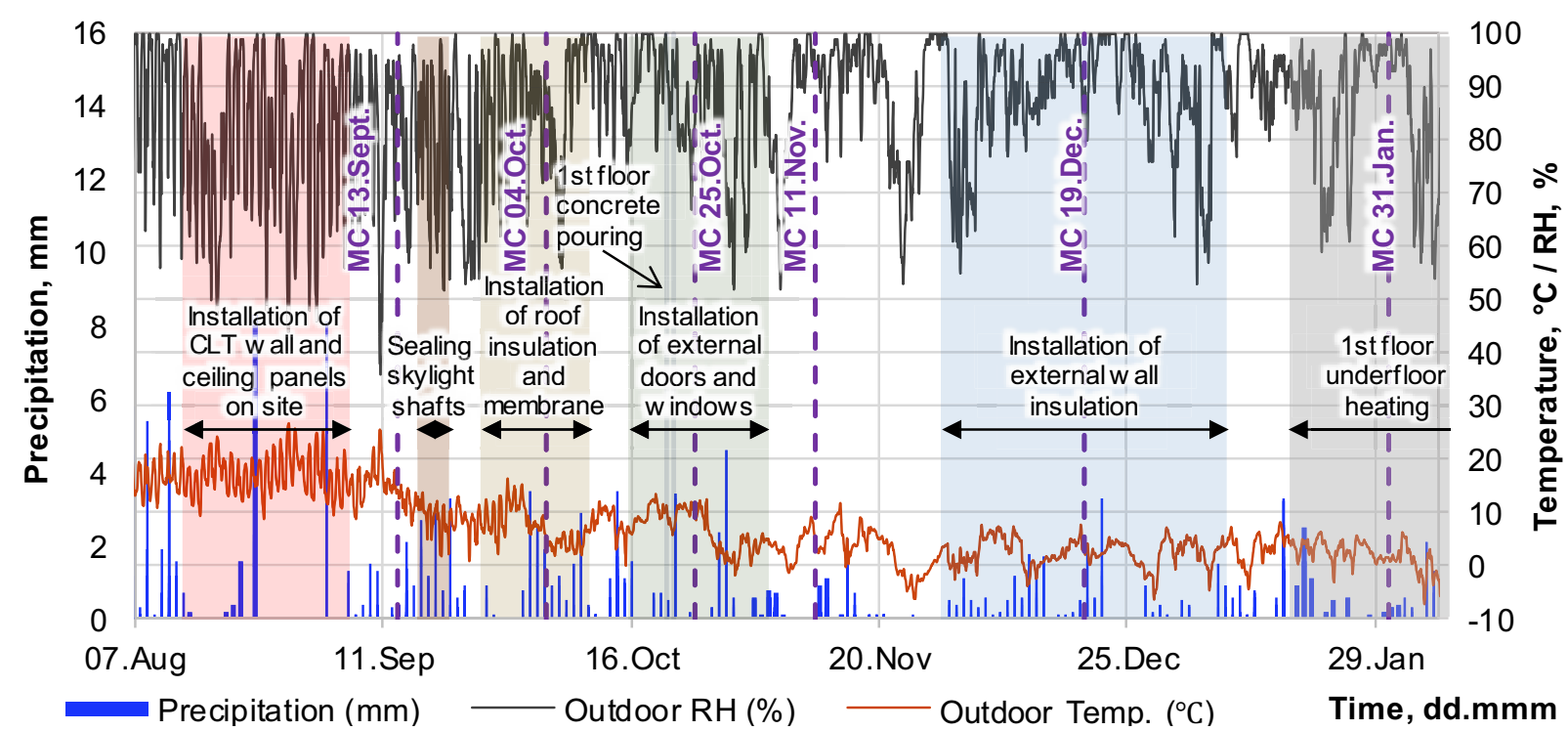

Fig. 3. Weather data during the construction period and MC measurements (MC 13 Sept.- MC 19 Dec.).

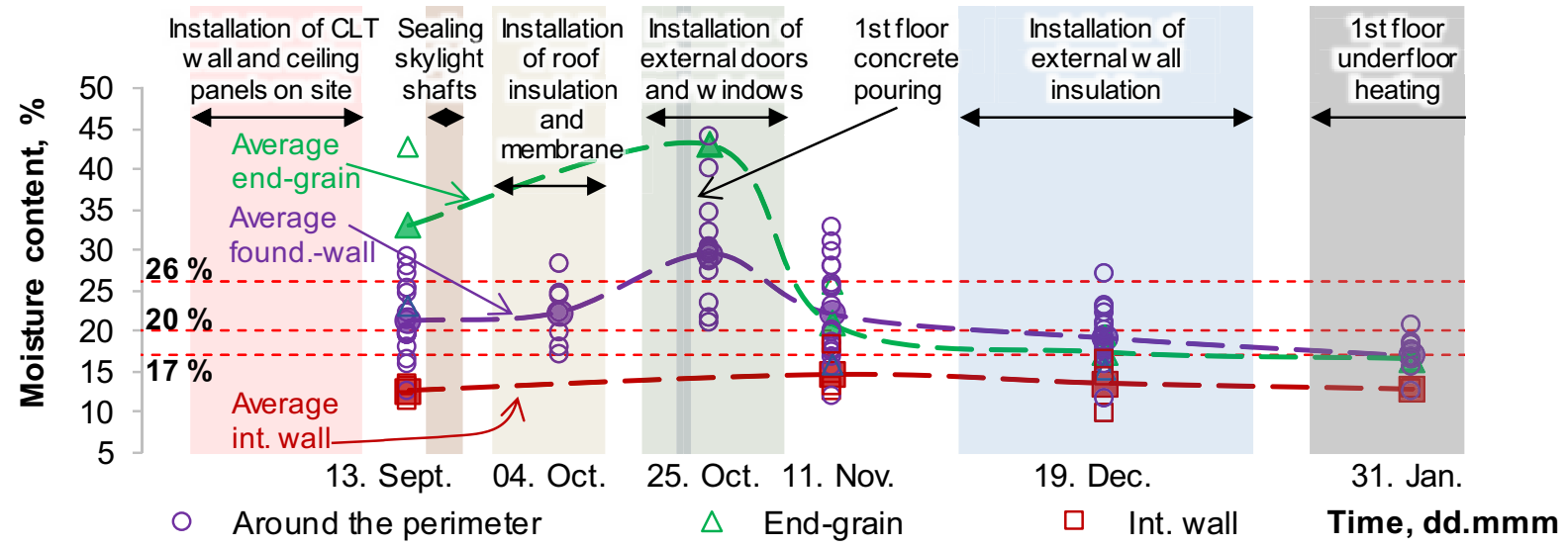

Fig. 4. MC of the CLT panels during distinct phases of construction. The filled markers show the average values of the measurements and the dashed lines represent the trend of average values. There were no measurements for the end grain on 4th October. The red dotted lines represent limiting values for mould growth and decay initiation.

The average outdoor temperature during the period was $8^{\circ} \mathrm{C}$ and the average relative humidity was $83 \%$.

The next construction phase was the installation of external doors and windows, between the $16^{\text {th }}$ October and $4^{\text {th }}$ November, which also included the first-floor concrete pouring on the $21^{\text {st }}$ and $22^{\text {nd }}$ October. The average precipitation was $0.8 \mathrm{~mm} / \mathrm{h}$ and the maximum reached $4.6 \mathrm{~mm} / \mathrm{h}$. We measured $\mathrm{MC}$ again on the $25^{\text {th }}$ October and the results showed a significant increase in MC. Average MC around the perimeter had risen to $29.5 \%$ and the average measured from end-grain reached $43 \%$. MC was above $20 \%$ in all points and exceeded $26 \%$ in most points. This phenomenon might have occurred because of the concrete pouring on the $1^{\text {st }}$ floor just before the measurements. Concrete pouring is a very moistureintensive task and leads to great moisture excess. This prohibited the moisture dry-out from the CLT and might have increased the moisture content on surface layers because of the hygroscopic properties of timber. Moreover, it is possible that some of the wet, uncured concrete could have made contact with the CLT (Fig. 5). This further confirms our suggestion that the most critical joint is the exterior wall to foundation connection.
Measurements taken 16 days later, on November $11^{\text {th }}$, showed that the average MC had fallen back to $22 \%$, but still half of the points had a MC more than $20 \%$ and five of them had more than $26 \%$. The outdoor average temperature was $7^{\circ} \mathrm{C}$ and the relative humidity was $87 \%$ during the installation of external door and windows.

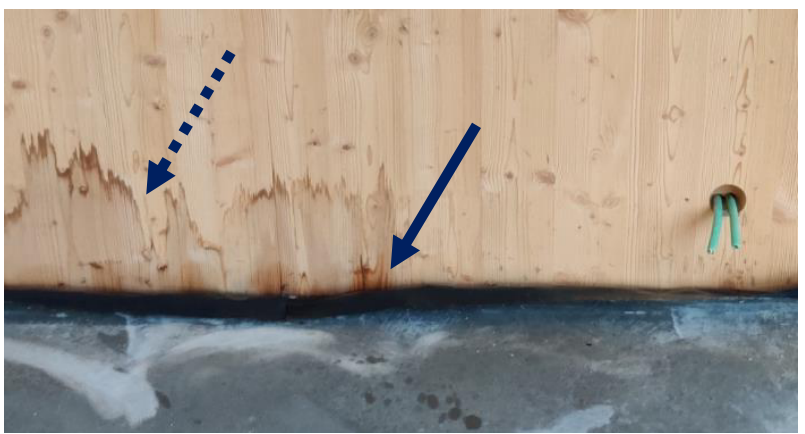

Fig. 5. CLT exterior wall and newly poured $1^{\text {st }}$ floor concrete screed. Note the discoloration of timber from the previous wetting incident (dashed arrow) and new wetting mark (solid arrow) possibly from the concrete pouring. 
The installation of external wall insulation was between November $29^{\text {th }}$ and January $8^{\text {th }}$. During this period the average precipitation amount was $0.4 \mathrm{~mm} / \mathrm{h}$ (maximum $3.3 \mathrm{~mm} / \mathrm{h}$ ). The average outdoor temperature was $2.4{ }^{\circ} \mathrm{C}$ and the average relative humidity was $89 \%$. However, after the windows and external doors were installed, a temporary air heating system was put into use, which increased the indoor temperature to about $15^{\circ} \mathrm{C}$ and reduced the indoor RH. This, together with the use of dehumidifiers, led to the decrease of timber MC. By December $19^{\text {th }}$, the average MC around the perimeter had dropped to $19.1 \%$ and the average of end-grain measurements dropped to $17.3 \%$. In most of the measured points the MC reached below $20 \%$.

The first-floor underfloor heating was turned on for the first time on January $17^{\text {th }}$. The last measurements were taken two weeks after on January $31^{\text {th }}$. The average MC around the perimeter was $16.9 \%$, the average of end-grain measurements was $16.5 \%$ and the average of intermediate wall was $12.7 \%$. The precipitation amount during the period between January $17^{\text {th }}$ and February $2^{\text {nd }}$ was the lowest among the entire observed period (average $0.3 \mathrm{~mm} / \mathrm{h}$ and maximum $2.1 \mathrm{~mm} / \mathrm{h}$ ). The average outdoor temperature was $2.9^{\circ} \mathrm{C}$ and the average relative humidity was $89 \%$. MC reached below $17 \%$ in most of the measured points during the last observed period.

In addition to the measurements at the exterior wall to foundation connection around the perimeter, we also measured the MC from the CLT panels at the intermediate ceiling to intermediate wall connection. The $\mathrm{MC}$ at this location was between $11 \%$ and $14 \%$ at the first measurement round. This was also the case for a panel covered with water, but as we measured $\mathrm{MC}$ from a fixed depth we detected an MC of $11 \%$ in the $30 \mathrm{~mm}$ deep layer. After the last round ( $31^{\text {th }} \mathrm{Jan}$.) the MC did not reach above $13 \%$. This indicates that intermediate CLT wall panels, which were more weather-protected, remained dry $(<17 \%)$ during the entire construction period.

We observed that the bottom edges of the CLT panels at the exterior wall to foundation connection were repeatedly exposed to rainwater and the measured MC of these regions remained consistently high throughout the observation period. The measurements from the end-grain showed that the initial high moisture content decreased after the installation of windows and external doors to a level at which the risk of moisture damage would not be expected. The areas where we could measure the MC in end-grain were open to indoor air and moisture dry-out was favourable. The MC measured from intermediate ceiling to intermediate wall connection remained low $(<17 \%)$ during the entire construction period. The intermediate walls were covered with ceiling and roof structures early during the installation of CLT panels and became protected from rain.

These results suggest that weather-protected structures stayed dry, and structures that were exposed to drying also reached a low MC over time, but in structures where drying was prohibited, the MC remained critical. This confirms our initial assessment as well as the need for weather protection for exterior wall to foundation connection. Schmidt et al. [18] also found in their laboratory test that the end grain of CLT panels in moisture trapping conditions were critical and could lead to a small accumulation of moisture during multiple cycles of wetting. Scotta et al. [19] claimed in their study that the foundation connection is the most critical and not completely solved in wooden buildings and where moisture damages are most likely to occur. They proposed to use a special self-developed aluminium bottom rail between the CLT wall panel and the foundation.

Mould growth rate depends greatly on the initial moisture content of the wood [20]. Several studies have shown that CLT in a closed wall assembly poses a risk of mould growth during service life if its MC exceeds $17 \%$ $[15,16]$. Although the MC levels decreased below the mould growth threshold for many of the measured locations, we still suggest making a mould growth analysis when the indoor temperature has been over $20^{\circ} \mathrm{C}$ for at least eight weeks.

Wetting not only poses a risk of microbial growth, but also affects the appearance of the wood surface by producing non-aesthetic stains. In the observed building, the CLT external wall panels will be used as interior decoration. Unfortunately, we noticed the "wetting marks" in numerous panels (e.g. Fig 5.). These proved to be difficult, costly and time-consuming to remove or alleviate. Drying out of moisture also causes volume shrinkage of the wood, which can result in noticeable cracks on the surface if the moisture content has been high. Large cracks were observed on the surfaces of the CLT panels in the given construction, which may result in lower airtightness of the building. V. Kukk et al. [21] and H. Skogstad et al. [22] found in their researches that cracks caused by volumetric shrinkage due to large changes in moisture content significantly increased the air leakage of CLT panels.

\subsection{Critical joints and improvement proposition}

After analysing the on-site measurements, we identified that the critical areas of precipitation-exposed CLT structures are on the cut edges of the CLT panels. This is mostly because the water absorption rate is much higher in the longitudinal direction of timber [23] and the endgrain part of the timber boards comprising the CLT are exposed on the cut edges.

Our observations led to the determination of six critical joints, where the end-grain is exposed to precipitation and where the moisture dry-out capacity is prohibited because of surrounding structures or the way the CLT panel is positioned in the joint. These joints are: 1) exterior wall to foundation connection (Fig. 6, a); 2) intermediate ceiling to intermediate wall connection (Fig. 6, b); 3) intermediate ceiling to external wall connection (Fig. 6, c); 4) intermediate ceiling to window connection (Fig. 6, d); 5) roof to exterior wall connection (Fig. 6, e), and 6) roof to skylight shaft connection (Fig. 6, f). On Figures $7-12$ there are the project drawings of these joints (left) and drawings with our proposal for wetting mitigation practices (right).

The most critical junction proved to be the exterior wall to foundation connection. There was a rubber band under the exterior wall edge to prevent moisture ingress, 

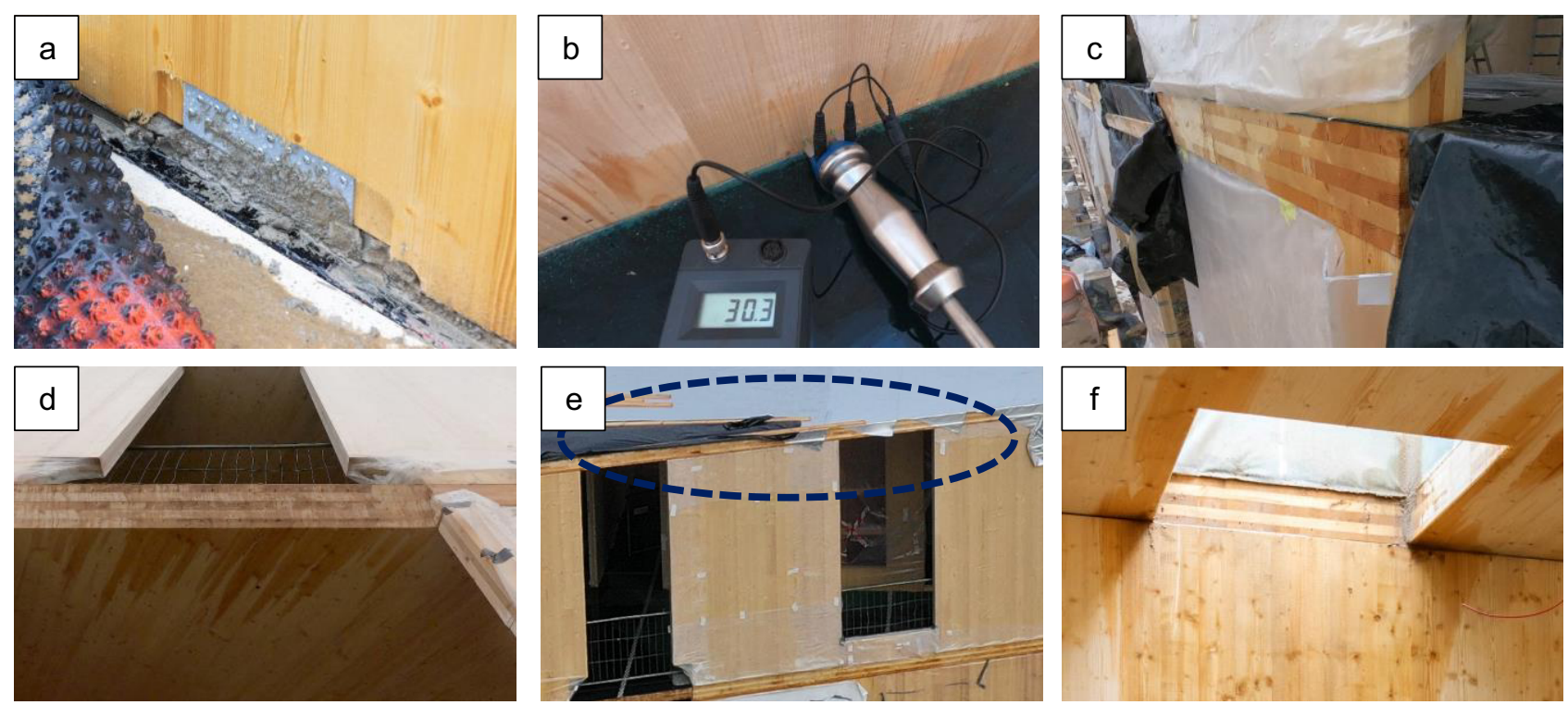

Fig. 6. Photographs of CLT junctions where wetting occurred frequently during our observation: a) exterior wall to foundation connection; b) intermediate ceiling to intermediate wall connection; c) intermediate ceiling to external wall connection; d) intermediate ceiling to window connection; e) roof to exterior wall connection and f) roof to skylight shaft connection.

but in many cases this solution did not prevent the wetting of the CLT (e.g. Fig. 6a). Water got between the rubber band and timber, thus decreasing the effectiveness of the rubber band. Moreover, the end-grain part around the fastening bracket was directly exposed to water. It was evident that sealing the fastening area with a rubber band is a complicated task. Therefore, in addition to the rubber band, we suggest using a liquid-applied membrane (Fig. 7), which must be installed in the factory and which will cover the whole cut-edge of the CLT panel regardless of cut-outs for fastening or other irregularities. Additionally, we suggest using a clear foil to protect the sides of the CLT panels from direct water contact. The foil must be clear, because it is then easier to detect accidental water flow behind it. The foil should also withstand strong winds. Thin packaging foils are thus not recommended. The foils must be fixed to the plinth immediately after installation with a water-resistant tape to prevent splashing water getting under the foil. An extra moisturesealing adhesive strip is necessary to make the CLT to concrete connection airtight. This adhesive strip will also further prevent water from getting under the CLT panel.

The same overall practice as described earlier should be followed with all the other junctions. Furthermore, the intermediate ceiling and roof panels must be covered with weather protection membranes (Fig. 8-12), because water could accumulate on the horizontal panels and cause critical wetting. The membrane used on the intermediate ceiling must be suitable for indoor use, i.e. not emitting harmful substances. The membranes on the horizontal panels must be installed in the factory and all the connection joints and feed throughs must be taped with water resistant tape on site immediately after the installation of the CLT panels. The membranes must tolerate loads e.g. from walking and storing construction materials and from brushing or vacuuming off excess water. The excess water must not drip over the edges of the intermediate ceiling nor the edge of the roof. To ensure this, a temporary wooden slat must be installed in front of the window opening and on the perimeter of the roof (Fig. 10, 11).

The wetting mitigation practices we proposed are developed on the example of a specific building. For other building projects, these solutions should be used as guidelines and adapted based on the specificity, complexity, construction time and size of each project.

If the ceiling and roof panels are installed immediately after intermediate wall panels, then the necessity to treat the cut edges of the intermediate walls is debatable. However, this is not often the case, especially for larger buildings and we suggest to always protect the cut edges of CLT, even the bottom edges of intermediate wall panels, to avoid wetting as in Figure $6 \mathrm{~b}$, where there is a weather protection membrane cover on the ceiling, but the intermediate wall is untreated and has visibly taken up water.

We suggest using the protective measures together with fast installation process and if wetting incidents do occur, then moisture must be dried out before covering the structures. 


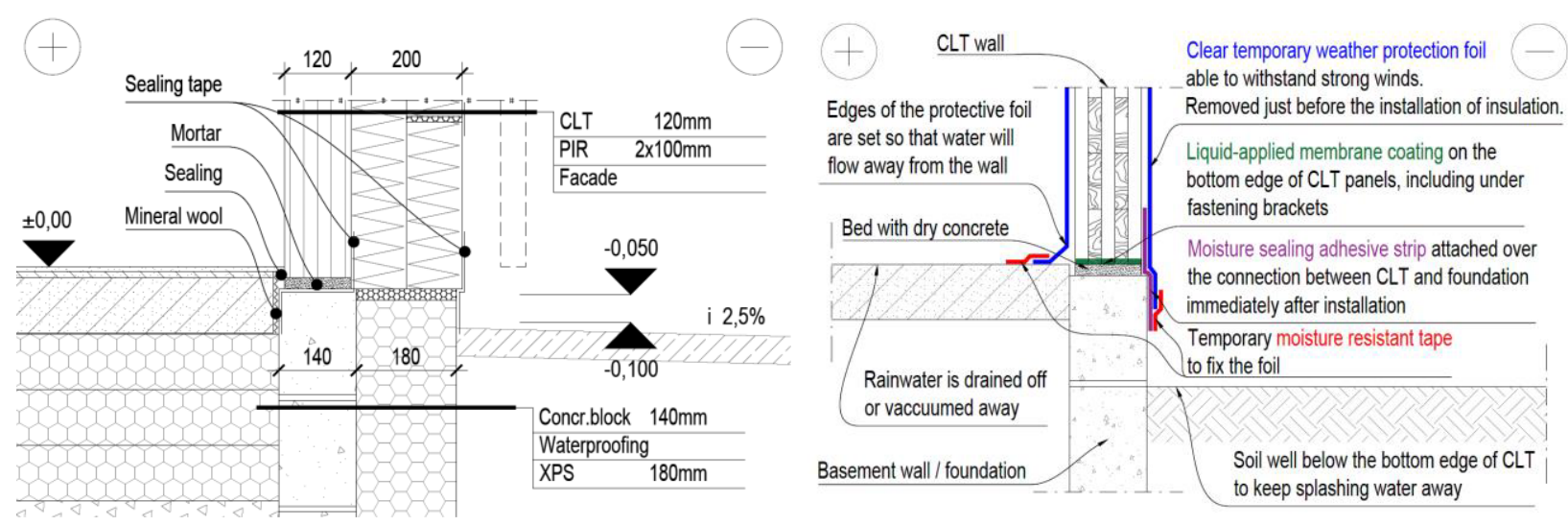

Fig. 7. Design drawing (left) of the exterior wall to foundation connection and our proposal (right) of wetting mitigation practices.
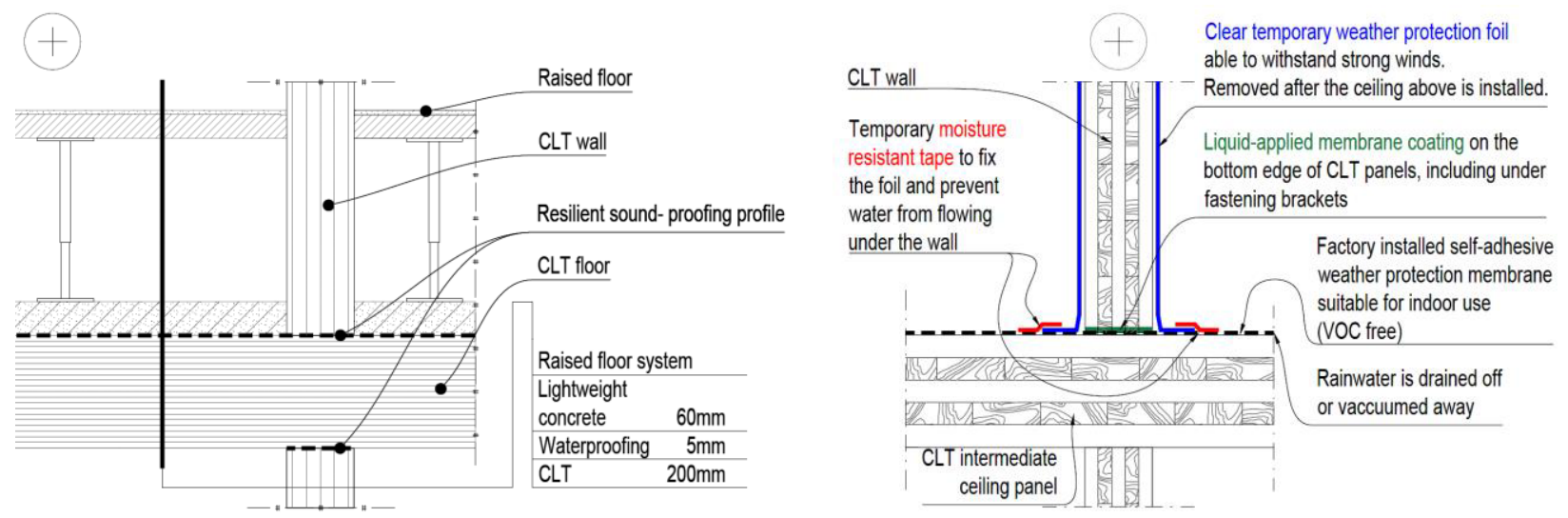

Fig. 8. Design drawing (left) of the intermediate ceiling to intermediate wall connection and our proposal (right) of wetting mitigation practices.
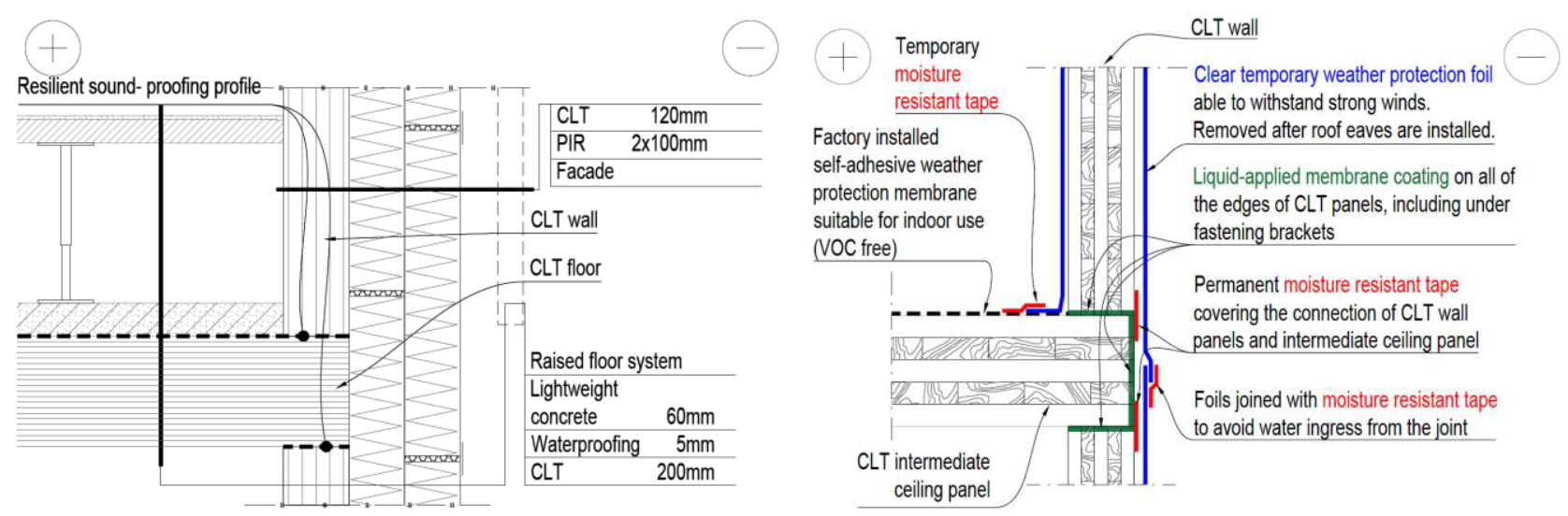

Fig. 9. Design drawing (left) of the intermediate ceiling to external wall connection and our proposal (right) of wetting mitigation practices. 

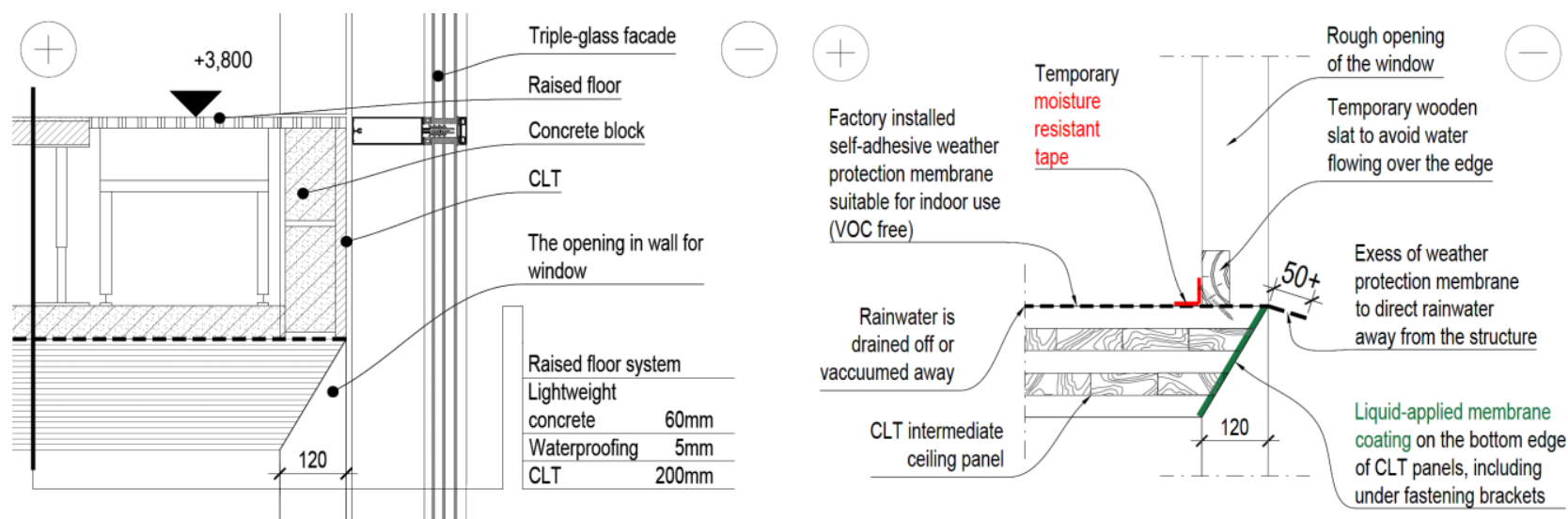

Fig. 10. Design drawing (left) of the intermediate ceiling to window connection and our proposal (right) of wetting mitigation practices.
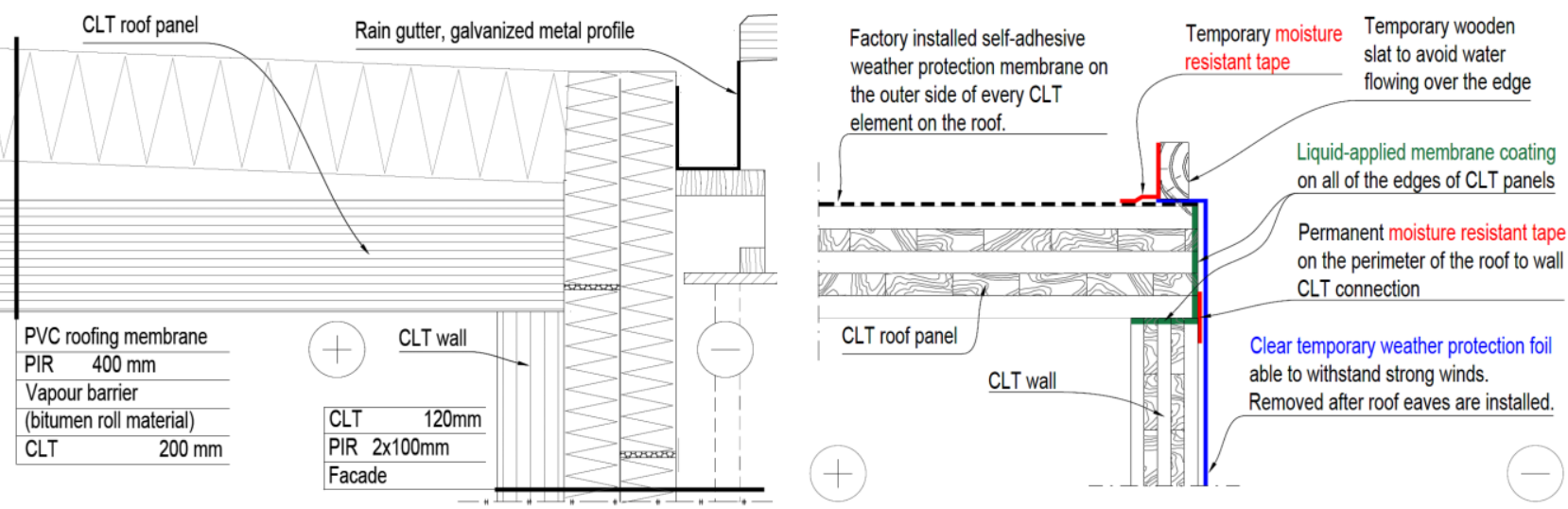

Fig. 11. Design drawing (left) of the roof to exterior wall connection and our proposal (right) of wetting mitigation practices.
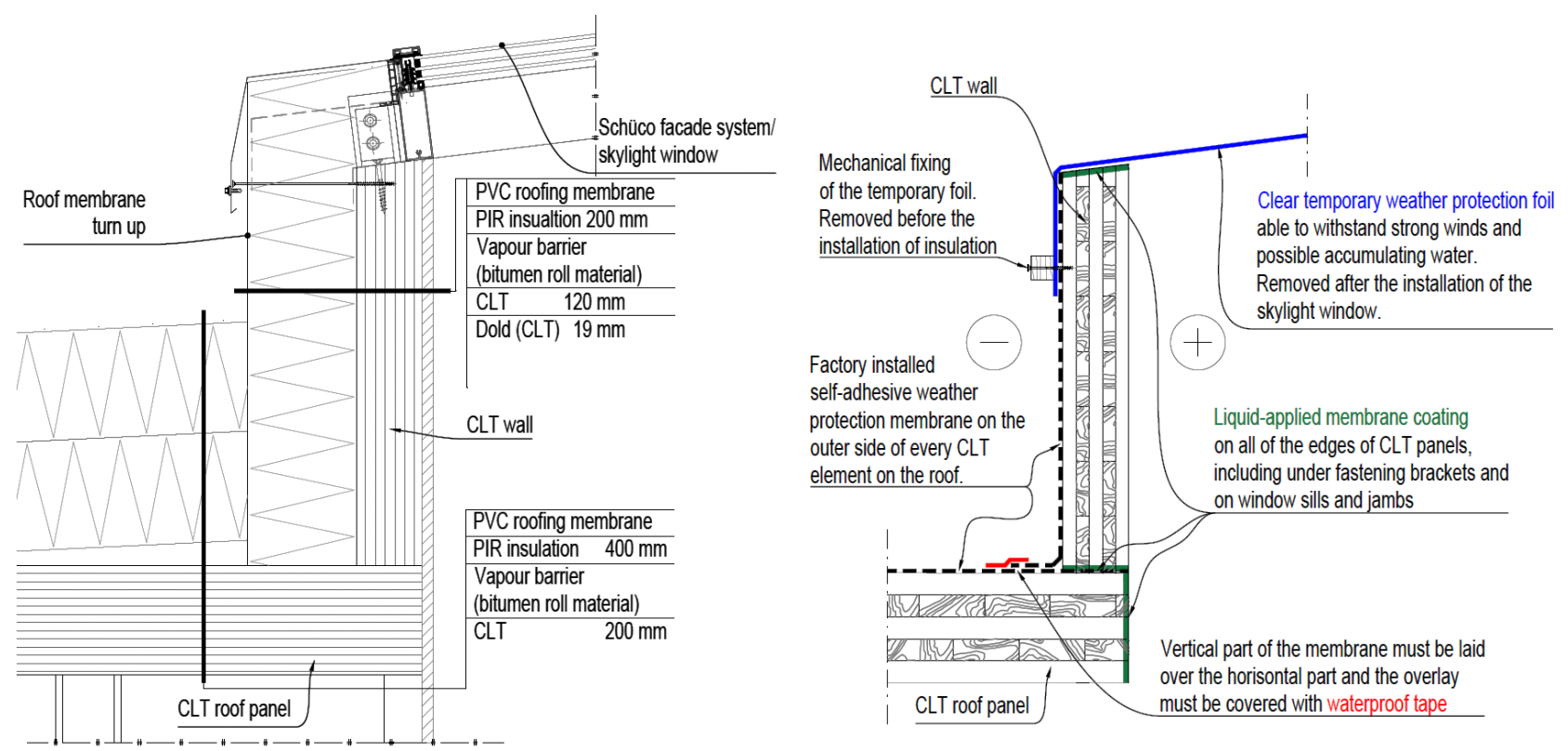

Fig. 12. Design drawing (left) of roof to skylight shaft connection and our proposal (right) of wetting mitigation practices. 


\section{Conclusions}

We observed the construction process of a CLT building over the course of about four months from the installation of CLT panels to the installation of exterior wall insulation. We made five measurement rounds to measure the moisture content in 25 specific spots determined on the first observation round. We identified the joints where most wetting incidents occurred, and the measured moisture content was the highest. Our findings correlate with other studies and showed that the most sensitive area to wetting is the end-grain on the CLT panel. When it was exposed to drying it reached a low MC level $(<17 \%)$ over time, but in structures where drying was prohibited, the $\mathrm{MC}$ remained within critical limits. Therefore, the most vulnerable section of the CLT structure is the foundation connection. Vulnerable joints are also the external wall and intermediate ceiling and roof connection and intermediate ceiling and window opening and intermediate wall connection, where the more water absorbing end-grain wood is exposed.

We suggest using liquid-applied membrane coating on the cut edges of CLT panels to protect the end grain. Additionally, we suggest protecting the horizontal CLT panels with self-adhesive membranes, and vertical CLT panels with temporary clear weather protection foils which can withstand strong winds. We provided drawings with specific descriptions of the wetting mitigation practices. These should be taken as general guidelines and should be adapted to every project specifically.

This research was supported by the Estonian Centre of Excellence in Zero Energy and Resource Efficient Smart Buildings and Districts, ZEBE (grant No. 2014-2020.4.01.150016) funded by the European Regional Development Fund and by the Estonian Research Council (grant No. PRG483), and by the European Commission through the H2020 projects Finest Twins (grant No. 856602) and NERO (grant No. 754177).

\section{References}

1. O. Schmidt, Wood and Tree Fungi: Biology, Damage, Protection, and Use (Springer, 2010)

2. V. Angst and K. A. Malo, European Journal of Wood and Wood Products 70, 603 (2012)

3. V. Angst and K. A. Malo, Wood Science and Technology 47, 227 (2013)

4. M. S. Jaakkola, H. Nordman, R. Piipari, J. Uitti, J. Laitinen, A. Karjalainen, P. Hahtola, and J. J. K. Jaakkola, Indoor Dampness and Molds and Development of Adult-Onset Asthma: A Population-Based Incident Case-Control Study (2002)

5. B. Crook and N. C. Burton, Fungal Biology Reviews 24, 106 (2010)

6. S. Hernberg, P. Sripaiboonkij, R. Quansah, J. J. K. Jaakkola, and M. S. Jaakkola, Respiratory Medicine 108, 677 (2014)
7. D. Caillaud, B. Leynaert, M. Keirsbulck, R. Nadif, S. Roussel, C. Ashan-Leygonie, V. Bex, S. Bretagne, D. Caillaud, A. C. Colleville, E. Frealle, S. Ginestet, L. Lecoq, B. Leynaert, R. Nadif, I. Oswald, G. Reboux, T. Bayeux, C. Fourneau, and M. Keirsbulck, European Respiratory Review 27, (2018)

8. CPR, Regulation (EU) No 305/2011 of the European Parliament and of the Council of 9 March 2011 Laying down Harmonised Conditions for the Marketing of Construction Products and Repealing Council Directive 89/106/EEC Text with EEA Relevance (2011)

9. L. Olsson and K. Mjörnell, Laboratory Investigation of Sills and Studs Exposed to Rain (2012)

10. T. Kalamees, Engineering Failure Analysis 9, 635 (2002)

11. K. Mjörnell and L. Olsson, Forum Wood Building Baltic (2019)

12. M. C. Peel, B. L. Finlayson, and T. A. McMahon, Hydrology and Earth System Sciences 11, 1633 (2007)

13. C. Williams, Journal of Business \& Economics Research (JBER) 5, (2011)

14. T. W. Edgar and D. O. Manz, in Research Methods for Cyber Security (Elsevier, 2017), p. 93

15. V. Kukk, A. Külaots, J. Kers, and T. Kalamees, Canadian Journal of Civil Engineering cjce (2019)

16. V. Kukk, J. Kers, and T. Kalamees, in 2019 Buildings XIV International Conference (ASHRAE, Clearwater, FL, 2019), pp. 599-607

17. R. McClung, H. Ge, J. Straube, and J. Wang, Building and Environment 71, 95 (2014)

18. E. L. Schmidt, M. Riggio, A. R. Barbosa, and I. Mugabo, Building and Environment 148, 609 (2019)

19. R. Scotta, D. Trutalli, L. Marchi, and L. Pozza, in Procedia Structural Integrity (2018), pp. 282289

20. S. A. Ahmed, M. Sehlstedt-Persson, and T. Morén, International Biodeterioration and Biodegradation 85, 284 (2013)

21. V. Kukk, T. Kalamees, and J. Kers, Journal of Building Physics 43, 171 (2019)

22. H. B. Skogstad, L. Gullbrekken, and K. Nore, in 9th Nordic Symposium on Building Physics (Tampere, Finland, 29.05 - 02 .06, 2011)

23. R. Shmulsky and P. D. Jones, Forest Products and Wood Science (Wiley-Blackwell, 2011) 